\title{
Leiomioma vesical de crecimiento extramural: Una presentación infrecuente - reporte de caso
}

\section{Extramural Growth Bladder Leiomyoma: An Infrequent Presentation - Case Report}

\author{
Luis Alejandro Guevara Morales ${ }^{1}$ Hugo Enrique López Ramos ${ }^{2}$ Juliana Alvarez Jaramillo ${ }^{3}$ \\ Diana Chaparro Orozco 4
}

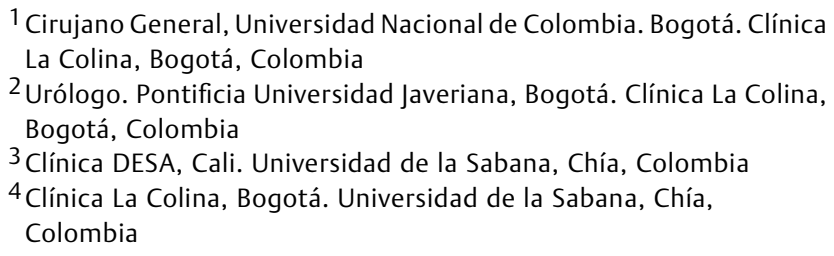

Address for correspondence Alvarez Jaramillo Juliana, MD, Cra 125\#16a-70, Cali, Valle del Cauca, Colombia (e-mail: julianaalja@gmail.com).

Urol Colomb 2019;28:35-38.

\section{Resumen}

Palabras Claves

- leiomioma

- vejiga urinaria

- neoplasia benigna

- tumor de vejiga
Introducción Los leiomiomas son tumores benignos de músculo liso y pueden encontrarse en cualquier parte del tracto urinario, la mayoría se origina en la vejiga. Se presentan más en mujeres y deben ser considerados como diagnóstico diferencial en cualquier tumor de vejiga. El objetivo de este trabajo es reportar el caso de una paciente con un hallazgo incidental de leiomioma de vejiga y de localización infrecuente; además de considerarse una patología poco frecuente.

Reporte de caso Paciente femenina de 40 años, ingresa por urgencias con cuadro de dolor abdominal en fosa iliaca derecha, valorada por cirugía general que realiza una presunción diagnóstica de apendicitis aguda y solicita estudios complementarios que evidencian proceso inflamatorio apendicular vs mucocele apendicular en la tomografía axial computarizada (TAC), por lo que se decide realizar apendicectomía por laparoscopia. Durante el procedimiento se evidencia lesión nacarada irregular dependiente de la cúpula vesical, por lo que se procede a interconsultar durante el procedimiento con el servicio de urología. El urólogo realiza cistoscopia sin evidencia de lesiones endoluminales. Se realiza excisión de la lesión junto con apendicectomía, sin complicaciones. La patología reporta leiomioma de vejiga.

Discusión y Conclusiones Los leiomiomas de vejiga son tumores benignos poco frecuentes. Por tratarse de una patología que infrecuentemente presenta síntomas, puede hallarse incidentalmente y debe ser tenida en cuenta como diagnóstico diferencial en presencia de masas vesicales. Las imágenes son de gran ayuda diagnostica, sin embargo, será la histopatología quien aporte el diagnóstico definitivo. El tratamiento podrá variar de acuerdo al tamaño y localización del tumor. received September 15, 2017 accepted November 15, 2017 published online April 30, 2018
DOI https://doi.org/ $10.1055 / \mathrm{s}-0038-1645847$. ISSN 0120-789X. eISSN 2027-0119.
Copyright ( 2019 , Sociedad Colombiana License terms de Urología. Publicado por Thieme Revinter Publicações Ltda., Rio de Janeiro, Brazil. Todos los derechos reservados.

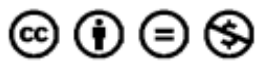




\begin{abstract}
Introduction Leiomyomas are benign smooth muscle tumor that can be found in any place of the urinary tract, most of them originated from the bladder. They are presented most frequently in women and must be considered as a differential diagnosis with any bladder tumor. The objective of this study is to present a case of a patient with an incidental finding of a bladder leiomyoma and infrequent location; besides being a rare disease.

Case Presentation Female patient of 40 years-old, attends the emergency room for abdominal pain in lower right quadrant. Is valorated by the surgery team, that suspected acute appendicitis and made complementary studies. The axial computerized tomography shows an inflammatory process in the cecal appendix vs appendicular mucocele. The patient was undertaken to appendectomy by laparoscopy. During the procedure, a nacreous irregular lesion dependent on the bladder dome was detected, the urology service was consulted intraoperatory call to the urology service was made. A cystoscopy was made, with no endoluminal lesions identified. An excision of the lesion and appendectomy were made without complications. Pathology of the lesion reported a bladder leiomyoma.

Keywords

- leiomyoma

- urinary bladder

- benign neoplasm

- bladder tumor

Discussion and Conclusion Bladder leiomyomas are very uncommon benign tumors. Most cases are asymptomatic, they are an incidental finding and should always be considered a differential diagnosis of any vesical mass. Images should be helpful diagnostic tool but the gold standard is the histopathological study. The treatment might change according to the size and location of the tumor.
\end{abstract}

\section{Introducción}

Los leiomiomas son tumores benignos del músculo liso. Pueden ser hallados en cualquier parte del tracto urinario, la mayoría se originan en la vejiga y corresponden al $1 \%-5 \%$ de los tumores de vejiga. ${ }^{1-4}$ Se presentan con mayor frecuencia en la población femenina y deben ser considerados como diagnóstico diferencial en cualquier tumor de vejiga. ${ }^{1}$ Son tumores que pueden ser asintomáticos a menos que afecten la función del tracto urinario inferior, generando síntomas urinarios obstructivos, irritativos y/o hematuria. La forma más común de presentación son los endovesicales (86\%), seguidos de extravesicales (30\%) quienes tienden a ser asintomáticos y de diagnóstico incidental. ${ }^{1,3,4}$ Las imágenes son de gran ayuda diagnóstica, sin embargo, el diagnóstico definitivo debe ser el informe histopatológico. ${ }^{5}$

El objetivo de este trabajo es reportar el caso de una paciente con un hallazgo incidental de leiomioma de vejiga cuya localización es infrecuente, además de tratarse de una patología de baja incidencia.

\section{Reporte de caso}

Paciente femenina de 40 años de edad, raza blanca, de profesión contadora, quien consulta al servicio de urgencias por cuadro de dolor abdominal severo de predominio en fosa iliaca derecha sin síntomas urinarios, que no reporta antecedentes médicos ni quirúrgicos. Valorada por el servicio de cirugía general quienes evidencian al examen físico, dolor a la palpación en fosa iliaca derecha además de signo de Blumberg positivo, lo cual sugiere probabilidad intermedia para apendicitis y solicitan paraclínicos los cuales se encuentran dentro de límites normales. En ecografía abdominal total se evidencia proceso inflamatorio de asas intestinales y miomatosis uterina; en la tomografía axial computarizada de abdomen contrastado se evidencia un proceso inflamatorio de íleon, así como proceso inflamatorio en el apéndice vs mucocele apendicular, por lo cual el servicio de cirugía considera realizar apendicectomía por laparoscopia. Durante dicho procedimiento se encuentra apéndice cecal hiperémico y congestivo además de lesión pétrea nacarada irregular de $3 \times 2 \mathrm{~cm}$ dependiente de lado derecho de cúpula vesical y peritoneo parietal adyacente; dado los hallazgos intraoperatorios se solicita valoración por el servicio de urología quienes realizan cistoscopia sin evidenciar cambios perilesionales endoluminales, posteriormente por medio de laparoscopia se libera la masa, quedando defecto de $2 \mathrm{~cm}$ en cúpula vesical. Posteriormente, se realiza cistorrafia y apendicectomía por laparoscopia, sin complicaciones.

Paciente asiste a control posoperatorio asintomática, con reporte de patología que evidencia apéndice con hiperplasia folicular linfoide reactiva y leiomioma de la cúpula vesical con cambios degenerativos. Se dan recomendaciones y signos de alarma y es dada de alta por ambos servicios (-Fig. 1).

\section{Discusión}

Dentro de los tumores de las vías genitourinarias, se considera a los tumores de vejiga como el segundo tumor 


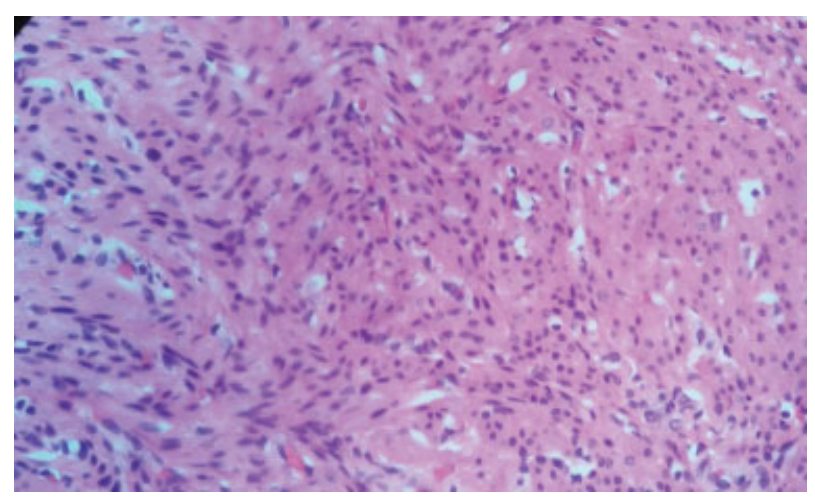

Fig. 1 Leiomioma de Vejiga.

maligno más común. Alcanzando el 7\% de nuevos casos por cáncer en hombres y $2 \%$ en mujeres. Con respecto a la histopatología, el $98 \%$ de todos los tumores de vejiga son de histogénesis epitelial. Sin embargo, se encuentra un grupo de tumores vesicales muy infrecuentes que corresponden a menos del $1 \%$ de todos los tumores de vejiga cuya histogénesis es mesenquimal o de origen mesequimatoso. Entre los que se encuentran leiomiomas, hemangiomas, sarcoma osteogénico y miosarcomas entre otros. ${ }^{5,6}$

Los Leiomiomas de vejiga fueron descritos por primera vez en 1870 por Jackson y solo existen aproximadamente 200 casos publicados en la literatura. ${ }^{7,8}$ En la vejiga, los leiomiomas son los tumores benignos mesenquimales más frecuentes, encontrándose en un $46,6 \%$ seguido por los hemangiomas en un $26,4 \%$ y otros tumores entre los que se incluyen fibromas, rabdomiomas, xantomas, dermoides, osteomas y mioblastomas de células granulosas. ${ }^{2}$ A diferencia de la mayoría de los tumores de vejiga, que se originan en el músculo liso. ${ }^{7}$

Los leiomiomas de vejiga presentan una mayor cantidad de casos reportados en la población femenina con una relación de 5:2. ${ }^{9}$ Han sido detectados en todos los grupos etarios, con un pico de ocurrencia entre tercera y sexta década de la vida y edad media de 44 años. ${ }^{3,7,10}$ Además, deben ser considerados como diagnóstico diferencial en cualquier tumor de vejiga. ${ }^{11}$ En una revisión sistemática realizada por Silvia-Ramos y col. con 90 pacientes, las principales características de sus pacientes fueron que el $75,6 \%$ eran mujeres, con una edad media de presentación de 45,3 años y los síntomas urinarios se manifestaron en el 50\% de los pacientes. ${ }^{12}$

La etiología de esos tumores benignos aún es desconocida. Teran y Gambrell proponen 4 teorías dentro de las cuales se encuentran los desórdenes hormonales, lo cual podría explicar su mayor incidencia en el género femenino, inflamación perivascular que conlleva a la transformación metaplásica de la vasculatura vesical, infecciones del detrusor de la vejiga que se asocian a inflamación y así la generación del tumor, y finalmente la disontogénesis, donde remanentes embriogénicos persisten en la vejiga generando los leiomiomas. ${ }^{3,5}$

Son tumores que permanecen silentes sin dar manifestaciones clínicas durante mucho tiempo, a menos que afecten la función del tracto urinario inferior $\mathrm{u}$ ocasionen sintomatología abdominal, siendo un hallazgo incidental en alguna exploración, cirugía o autopsia. ${ }^{2}$ En nuestro caso, el leiomioma de vejiga fue un hallazgo incidental durante un procedimiento quirúrgico, además de no haber generado síntomas urinarios que alteraran el tracto urinario inferior. Jong Wook y col. describen en su reporte de 9 casos, la relación del tamaño del tumor y la posibilidad de generar algún tipo de sintomatología, donde el diámetro de $3 \mathrm{~cm}$ es la referencia para el desencadenamiento de los mismos. ${ }^{5}$ Si el tumor presenta sintomatología, dependerá de su localización al igual que de su tamaño, dentro de los más frecuentes podemos encontrar síntomas urinarios obstructivos en un $49 \%$, síntomas irritativos $38 \%$, hematuria $11 \%$ y dolor en flanco $13 \%$. $1,3,4,10$

Tres formas de leiomiomas vesicales han sido descritas en la literatura: endovesical (63\%-86\%), extravesical (11\%-30\%) e intramural (3\%-7\%). Generalmente, la forma depende de la localización predominante del tumor. La forma más frecuente es la endovesical que protruye hacia la vejiga, y por lo tanto puede generar síntomas más fácilmente; usualmente de tipo irritativo y hematuria; a diferencia de los intramurales, que tienden a ser asintomáticos y son de diagnóstico incidental. ${ }^{3,7,10}$ En el caso reportado anteriormente, la forma de presentación fue inusual, contrario a la reportada como más frecuente en la literatura, ya que el leiomioma era de presentación extramural y no intramural como se presentan más habitualmente.

El diagnóstico suele ser incidental mediante imágenes diagnosticas como la ecografía que permite diferenciar tanto la naturaleza quística o sólida de la masa vesical, como los límites y la relación con los órganos vecinos. ${ }^{2}$ En la tomografía axial computarizada en la que se puede observar una imagen homogénea, sólida con márgenes bien definidas; la resonancia magnética resulta ser de mayor utilidad, permitiendo demostrar su origen en la submucosa y preservación de la capa muscular, además de diferenciar los tumores epiteliales (cuya mayoría son transicionales). ${ }^{1,7}$ En ese caso, las imágenes no fueron de gran ayuda para el diagnóstico, pues se sospechó un proceso intestinal y apendicular más que una probable lesión de vejiga, la cual no fue mencionada en las imágenes.

Es importante realizar una adecuada historia clínica y un examen físico completo, pues se ha reportado en un $50 \%$ lesiones palpables en mujeres con exploración bimanual. ${ }^{1}$ Imágenes diagnosticas complementarias como la urografía excretora o cistouretrografía puede identificar defectos de llenado en la vejiga. La ecografía pélvica puede revelar una masa submucosa sólida en la vejiga que se relaciona con el útero y la vagina. ${ }^{1}$ La cistoscopia puede usarse para distinguir de los tumores endovesicales de intramurales. Los tumores endovesicales son resultados del crecimiento submucoso del leiomioma, generalmente son polipoides o pedunculados, mientras que los intramurales son bien encapsulados $\mathrm{y}$ rodeados de pared muscular de la vejiga. ${ }^{3}$

Aunque las imágenes son ayuda para la detección de esas masas, el diagnóstico definitivo es exclusivamente histopatológico, en el que se puede excluir el diagnóstico 
diferencial de leomiosarcoma. En el presente caso, el estudio histopatológico confirmó la presencia de leiomioma de presentación extramural en la vejiga de la paciente. Los leiomiomas de vejiga macroscópicamente pueden ser tan pequeños como menores de $2 \mathrm{~cm}$ o tan grandes como de hasta $25 \mathrm{~cm}$ y característicamente son masas pediculadas o polipoides. Histológicamente se ven paquetes entrelazados de músculo liso con urotelio benigno subyacente, además sus células posen tamaño y formas uniformes con citoplasma eosinofílico y núcleo oval característico. Puede tener atipia mínima y poca mitosis. Además no debe existir necrosis en el tejido examinado, ya que eso podría ser sugestivo de leiomiosarcoma. ${ }^{13,14}$

Inmunohistoquímicamente los leiomiomas de vejiga son positivos para actina, desmina y vimentina, y negativos para citoqueratina y para proteína $\mathrm{S} 100 .{ }^{5,13,14}$

Se han descrito la presencia de receptores para estrógenos en los leiomiomas vesicales, razón por la cual se asociaría la influencia de los estrógenos con el crecimiento de los leiomiomas y su infrecuente aparición antes de la pubertad, su mayor incidencia entre la cuarta y quinta década donde las hormonas se encuentran sustancialmente activas, y la disminución del tamaño tumoral posterior a la menopausia. ${ }^{5,8}$

En cuanto al tratamiento de los leiomiomas, es posible determinarlo de acuerdo al tamaño, localización anatómica y compromiso de estructuras adyacentes como esfínter o meatos ureterales. ${ }^{1,7}$ La resección transuretral y cirugía abierta se han reportado y comparado en estudios previos; Vargas y Méndez han recomendado la resección transuretral como manejo definitivo. El $62 \%$ de los pacientes fueron tratados con resección abierta, mientras que el 30\% restante fueron llevados a resección transuretral de la lesión. Los tumores pequeños pueden ser resecados de forma transuretral. Solo el 18\% requieren reintervención debido a resección incompleta. En casos de cirugía abierta la mayoría de los autores recomiendan la cistectomía parcial como el tratamiento de elección. ${ }^{10}$ Debido al excelente pronostico y la no transformación de malignidad de los pacientes posterior al tratamiento quirúrgico, el seguimiento no se recomienda a excepción que presenten síntomas urinarios. ${ }^{14}$

\section{Conclusiones}

En resumen, los leiomiomas de vejigas son tumores benignos de músculo liso poco frecuentes. Por tratarse de una patología la mayoría de las veces asintomática, generalmente se diagnostican de forma incidental como en el caso reportado y además de tener presentación extramural la cual es infrecuente. Deben tenerse en cuenta siempre como diagnóstico diferencial en masas vesicales. Las imágenes son de gran ayuda diagnóstica, sin embargo, será la histopatología quien aporte el diagnóstico definitivo y el tratamiento será variable de acuerdo al tamaño y localización del tumor.

\section{Conflictos de intereses}

No se declara ningún conflicto de interés

Protección de personas y animales

Los autores declaran que para esta investigación no se han realizado experimentos en seres humanos ni en animales.

Confidencialidad de los datos

Los autores declaran que han seguido los protocolos de su centro de trabajo sobre la publicación de datos de pacientes.

Derecho a la privacidad y consentimiento informado Los autores han obtenido el consentimiento informado de los pacientes y/o sujetos referidos en el artículo. Este documento obra en poder del autor de correspondencia.

\section{Bibliografía}

1 Chen $\mathrm{CC}$, Huang $\mathrm{CH}$, Chu $\mathrm{CH}$, y col . Leiomyoma of the urinary bladder: a case report. Kaohsiung J Med Sci 2003;19(03):141-145

2 Jiménez Aristu JI, Lozano Uruñuela F, de Pablo Cárdenas A, y col . Leiomioma de vejiga. A propósito de un caso. Actas Urol Esp 2001; 25(03):223-225

3 Khater N, Sakr G. Bladder leiomyoma: Presentation, evaluation and treatment. Arab J Urol 2013;11(01):54-61

4 Matsushima M, Asakura H, Sakamoto H, Horinaga M, Nakahira Y, Yanaihara $\mathrm{H}$. Leiomyoma of the bladder presenting as acute urinary retention in a female patient: urodynamic analysis of lower urinary tract symptom; a case report. BMC Urol 2010;10:13

5 Park JW, Jeong BC, Seo SI, Jeon SS, Kwon GY, Lee HM. Leiomyoma of the urinary bladder: a series of nine cases and review of the literature. Urology 2010;76(06):1425-1429

6 McAninch J, Lue T. Smith y Tanagho Urología General. 18 Ed. 2014 Editorial.

7 Castro-gaytán A, Cisneros-madrid B, Montes-mojarro I, Lomelínramos JP. Leiomioma vesical. Reporte de un caso. Rev Mex Urol 2015;75(01):42-45

8 Xin J, Lai HP, Lin SK, y col . Bladder leiomyoma presenting as dyspareunia: Case report and literature review. Medicine (Baltimore) 2016;95(28):e3971

9 Elías RC, Rico D, Rodríguez R, Otegui R, Cura R, Basaldúa L. Leiomioma vesical: reporte de un nuevo caso $\mathrm{y}$ revisión bibliográfica Bladder leiomyoma: a new case report and bibliographic review. 2013;78 (July 2012):2012-4.

10 Lin HC, Wu WJ, Ke HL, Huang CH. Bladder leiomyoma presenting as voiding dysfunction: a case report. Kaohsiung J Med Sci 2006; 22(03):154-157

11 Iglesias BR, Delgado JB. Leiomioma Vesical. 2001;759-63

12 Silva-Ramos M, Massó P, Versos R, Soares J, Pimenta A. Leiomioma de vejiga. Análisis de agregación de 90 casos. Actas Urol Esp 2003; 27(08):581-586

13 Kumar V, Abbas A, Aster J. Patologia Estructural y Funcional Robbins y Cotran. Novena Ed. 2015 Editorial.

14 Park JW, Jeong BC, Seo SI, Jeon SS, Kwon GY, Lee HM. Leiomyoma of the urinary bladder: a series of nine cases and review of the literature. Urology 2010;76(06):1425-1429 10.1016/j.urology.2010.02.046 